\title{
Is the Distribution of Microorganisms and Peritonitis Affected by Seasonality in Peritoneal Dialysis?
}

\author{
Ana Elizabeth Figueiredo', Ana Carolina Gonçalves Kehl², Stephanie Thomaz Bottin², \\ Wilem Gomes Daminelli² \\ ${ }^{1}$ School of Nursing, Nutrition and Physiotherapy (FAENFI), Pontifícia Universidade Católica do Rio \\ Grande do Sul (PUCRS), PUCRS, Porto Alegre, Brazil \\ ${ }^{2}$ Hospital São Lucas da Pontifícia, Universidade Católica do Rio Grande do Sul, Porto Alegre, Brazil \\ Email: anaef@pucrs.br
}

Received 11 November 2014; revised 10 December 2014; accepted 19 December 2014

Copyright (C) 2014 by authors and Scientific Research Publishing Inc.

This work is licensed under the Creative Commons Attribution International License (CC BY). http://creativecommons.org/licenses/by/4.0/

(c) (7) Open Access

\section{Abstract}

Introduction: Peritonitis continues to be the main complication for patients on peritoneal dialysis (PD). Objective: To determine the frequency of peritonitis according to the disease-causing microorganism and its distribution throughout the year, linking to seasonality. Methods: A retrospective study conducted in the Dialysis Unit of the Hospital São Lucas, PUCRS (HSL-PUCRS). Patients undergoing PD between January 1984 and September 2013 were included. Descriptive statistics were used and Fisher's exact test with Monte Carlo simulation for comparison between the categorical variables. Results: Of 415 evaluated patients, $66 \%$ had at least one episode of peritonitis with an incidence rate of 0.68 episode/year. There were 601 peritonitis episodes in total. The most common microorganism was coagulase-negative Staphylococcus $(26.6 \%, n=160)$, followed by Staphylococcus aureus $(16.3 \%, \mathrm{n}=98)$, with $16.3 \%$ of the sample being negative culture. Most episodes occurred in the months of January $(10.3 \%, n=62)$ and May $(10.1 \%, n=61)$, while June had the lowest occurrence $(5.2 \%, n=31)$. The number of episodes observed in January and May were significantly higher when compared to June $(p<0.001)$. No significant differences were found for the remaining months. There was no association between the microorganisms and months of the year $(p=0.841)$. Conclusion: The rate of peritonitis is in line with that recommended by the International Society for Peritoneal Dialysis. The distribution of peritonitis-causing germs over the months of the year would seem to be random.

\section{Keywords}

Chronic Renal Insufficiency, Peritoneal Dialysis, Peritonitis, Seasonal Variations 


\section{Introduction}

Peritonitis in peritoneal dialysis (PD) continues to be one of the principal complications of this type of dialysis and identification of the modifiable risk factors can contribute to the reduction of morbidity [1]. Among the main causes for interruption of a PD program are: Peritonitis, catheter infection and ultrafiltration failure [2]. Lower rates of peritonitis can be achieved when risk reduction protocols are implemented [3]. The microorganisms that cause peritonitis may be used as an indicator of the route of contamination, the most frequent routes being: Intraluminal through accidental touch contamination of the open access during connection/disconnection of the dialysis bag, periluminal or contamination [4]. Gram-positive bacteria are the main pathogens causing peritonitis [5]. The most common microbial agent in Brazil and in the majority of Latin American countries is Staphylococcus aureus and is associated with more severe episodes with a greater risk of hospitalization, catheter removal and death [6]. Historically, the Nephrology Service of the Hospital São Lucas, Pontifical Catholic University of Rio Grande do Sul (HSL-PUCRS) has presented a higher prevalence of Coagulase-Negative Staphylococci (CNS), followed by peritonitis caused by Staphylococcus aureus and negative cultures [7] [8].

Peritonitis is mainly caused by CNS and Staphylococcus aureus, accounting for $80 \%$ of cases associated to intraluminal or periluminal contamination [9]. The presence of Staphylococcus aureus nasal carriers among chronic kidney disease patients is common, increasing the chance of skin colonization and leading to infection of the catheter exit-site, and peritonitis as a consequence [3] [10]-[12]. However, there is conflicting information regarding the seasonal distribution of peritonitis.

The aim of this study was to determine the distribution of peritonitis according to the disease-causing microorganisms and time of year.

\section{Methods}

A retrospective, descriptive and quantitative study was conducted. The sample was composed of patients undergoing PD at the Nephrology Service of the HSL-PUCRS between the years of 1984 and September 2013, during a period equal to or greater than 90 days. The years 1989 to 1992 were excluded due to a lack of complete medical records, and pediatric patients. The data collected included: name, age, gender, birth date, beginning and end of PD, duration of treatment, date of first peritonitis, numbers of peritonitis, month of the year and causing microorganisms.

The results are presented as absolute (n) and relative (\%) distributions of categorical variables and mean \pm standard deviation for continuous variables. Fisher's exact test with Monte Carlo simulation was used for comparison between the categorical variables.

The software SPSS 20.0 (Statistical Package for Social Sciences for Windows-SPSS Inc., Chicago, IL, USA, 2010) was used for statistical analysis of the data, with a $5 \%$ level of significance $(\alpha)$ adopted.

This study was approved by the Research Ethics Committee of PUCRS under protocol number 09/04535. The confidentiality of all data collected from patient-related medical records and databases attended by the Nephrology Service of the HSL-PUCRS was assured.

\section{Results}

From the 427 patients recorded in the hospital databank from January 1984 until September 2013, 415 met the study inclusion criteria. Sixty-six percent of patients had at least one episode of peritonitis with an incidence rate of 0.68 episode/year. Of these patients, 221 (53.25\%) were women with a mean age of $48 \pm 19.9$ years and a mean time from the start of PD treatment to the first occurrence of peritonitis of $209 \pm 68$ days; the mean duration for undergoing PD was 545 days with a minimum of 91 days and maximum of 4692 days. During this period, 601 cases of peritonitis were recorded and these were distributed over the months from January to December according to their occurrence.

The distribution of peritonitis cases over the months of the year, have shown that the largest number of cases occurred in the months of January $(10.3 \%, \mathrm{n}=62)$ and May $(10.1 \%, \mathrm{n}=61)$, while the month with the least occurrences was June $(5.2 \%, \mathrm{n}=31)$. A comparison of data verified that the peritonitis episodes recorded in January and May were significantly higher when compared with June $(\mathrm{p}<0.001)$. No significant differences were found in relation to the other months of the year.

It was observed when classifying bacteria by the Gram test that gram-negatives (Pseudomonas sp., Escheri- 
chia coli, Enterobacter sp., Klebsiella sp.) were more prevalent in the month of February $(12.6 \%, \mathrm{n}=13)$, as well as in January and December, which presented the same percentage $(11.7 \%, \mathrm{n}=12)$; the gram-positives (Staphylococcus coagulase negative, Staphylococcus aureus, Streptococcus sp., Enterococcus sp.) occurred more in the months of May $(10.8 \%, \mathrm{n}=34)$ and January $(10.1 \%, \mathrm{n}=32)$. The distribution throughout the year is presented in Figure 1.

Peritonitis with a negative culture had a higher prevalence in August $(17.3 \%, \mathrm{n}=17)$. Eosinophilic peritonitis and the microorganisms that occurred sporadically were classified as others (Proteus sp., Coryneumbacterium sp., Acinetobacter sp., Alcaligene sp.) with the greatest frequency of occurrence being in the months of May, July and December, in the same number of cases for each $(16.7 \%, n=8)$. No record of the causative microorganism was found on the peritonitis control sheets for some episodes of the disease $(6.8 \%, n=41)$.

Table 1 presents the types of microorganisms involved; cases defined as gram-positive $(52.6 \%, n=316)$ were

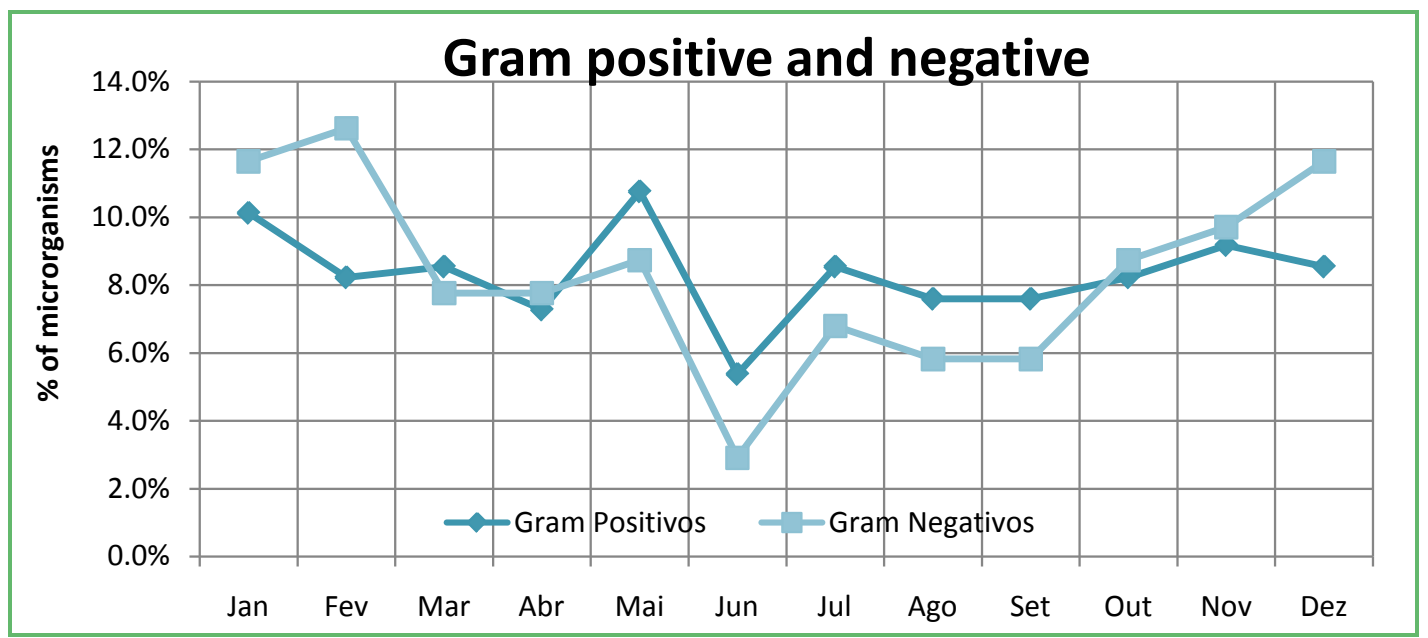

Figure 1. Distribution of microorganisms Gram Positive and Gram Negative during the months of the years.

Table 1. Absolute and relative distribution for the total occurrence of microorganism cases.

\begin{tabular}{|c|c|c|c|c|c|c|c|c|c|c|c|c|}
\hline \multirow{3}{*}{ Month $^{*}$} & \multicolumn{12}{|c|}{ Classification of Microorganisms } \\
\hline & \multicolumn{2}{|c|}{ Gram-Negatives } & \multicolumn{2}{|c|}{ Gram-Positives } & \multicolumn{2}{|c|}{ Fungi } & \multicolumn{2}{|c|}{ Negative Culture } & \multicolumn{2}{|c|}{ Others } & \multicolumn{2}{|c|}{$\begin{array}{l}\text { Month } \\
\text { Total }^{* *}\end{array}$} \\
\hline & $\mathrm{N}$ & $\%$ & $\mathrm{~N}$ & $\%$ & $\mathrm{~N}$ & $\%$ & $\mathrm{~N}$ & $\%$ & $\mathrm{~N}$ & $\%$ & $\mathrm{~N}$ & $\%$ \\
\hline Jan & 12 & 11.7 & 32 & 10.1 & 2 & 12.5 & 11 & 11.2 & 5 & 7.4 & 62 & 10.3 \\
\hline Feb & 13 & 12.6 & 26 & 8.2 & 1 & 6.3 & 7 & 7.1 & 2 & 2.9 & 49 & 8.2 \\
\hline Mar & 8 & 7.8 & 27 & 8.5 & 2 & 12.5 & 6 & 6.1 & 6 & 8.8 & 49 & 8.2 \\
\hline Apr & 8 & 7.8 & 23 & 7.3 & 3 & 18.8 & 9 & 9.2 & 6 & 8.8 & 49 & 8.2 \\
\hline May & 9 & 8.7 & 34 & 10.8 & 2 & 12.5 & 8 & 8.2 & 8 & 11.8 & 61 & 10.1 \\
\hline Jun & 3 & 2.9 & 17 & 5.4 & & 0 & 5 & 5.1 & 6 & 8.8 & 31 & 5.2 \\
\hline Jul & 7 & 6.8 & 27 & 8.5 & 1 & 6.3 & 9 & 9.2 & 7 & 10.3 & 51 & 8.5 \\
\hline Aug & 6 & 5.8 & 24 & 7.6 & 2 & 12.5 & 17 & 17.3 & 4 & 5.9 & 53 & 8.8 \\
\hline Sept & 6 & 5.8 & 24 & 7.6 & 1 & 6.3 & 7 & 7.1 & 6 & 8.8 & 44 & 7.3 \\
\hline Oct & 9 & 8.7 & 26 & 8.2 & 1 & 6.3 & 10 & 10.2 & 7 & 10.3 & 53 & 8.8 \\
\hline Nov & 10 & 9.7 & 29 & 9.2 & 1 & 6.3 & 4 & 4.1 & 3 & 4.4 & 47 & 7.8 \\
\hline Dec & 12 & 11.7 & 27 & 8.5 & & 0 & 5 & 5.1 & 8 & 11.8 & 52 & 8.7 \\
\hline Total & 103 & 17.1 & 316 & 52.6 & 16 & 2.7 & 98 & 16.3 & 68 & 11.3 & 601 & 100 \\
\hline
\end{tabular}

* Percentages obtained based on the total of each classification; ${ }^{* *}$ Percentages obtained based on the overall total (n = 601). 
significantly higher when compared to gram-negative $(17.1 \%, \mathrm{n}=103)$; negative cultures $(16.3 \%, \mathrm{n}=98)$; others $(11.3 \%, \mathrm{n}=68)$; and fungi $(2.7 \%, \mathrm{n}=16)(\mathrm{p}<0.001)$.

The highest prevalence was of Staphylococcus epidermidis or coagulase-negative (26.6\%, $\mathrm{n}=160$ ), followed by Staphylococcus aureus and negative culture, each representing $16.3 \%(n=98)$ of the cases. The proportion of cases of Staphylococcus epidermidis or coagulase negative was significantly higher in comparison with the other microorganisms, as was also the case when comparing Staphylococcus aureus and negative culture with the other microorganisms.

When considering the most prevalent microorganisms and in accordance with Table 2, a statistically significant association $(\mathrm{p}<0.0001)$ was detected in evaluating the relationship between the microorganisms involved and months of the year.

The association between the etiologic agents of peritonitis and months of the year was not confirmed $(\mathrm{p}=$ 0.841), indicating that peritonitis was not seasonally dependent for this studied sample; distribution was random.

\section{Discussion}

Analysis of the dialysis service for peritonitis episodes showed the rate to be within the minimum recommended by the International Society for Peritoneal Dialysis (ISPD), and similar to other Brazilian studies [13] [14].

Census data from the Brazilian Society of Nephrology reported 31.9\% of patients receiving renal replacement therapy were greater than or equal to 65 years of age, with a higher incidence of men at $57.7 \%$, whereas the present study presented a younger population with more women [15].

Cho et al. [16] in a study conducted in Australia and Kim et al. [17] in a Korean study demonstrated a higher incidence of peritonitis in the summer months, similar to our findings. Alterations in temperature and humidity that accompany seasonal change may potentially be related to patient hygiene behavior, distribution of normal skin flora and the chance of contamination [16].

A Brazilian study involving health professionals in relation to compliance with hand hygiene techniques showed a decrease in compliance in the summer months, which was associated with the Christmas festivity, vacation and summer period [18]. The same can occur with PD patients and may be aggravated by it being a home therapy; the summer could change household conditions and this may contribute to the rise in infections.

The initial hypothesis that there was a decrease in hand hygiene during the winter months with a consequent increase in peritonitis rates was not confirmed; this probably indicates that hand hygiene is not the only factor contributing to infections. No other study with similar results was encountered.

Table 2. Relative distribution of microorganisms according to month.

\begin{tabular}{|c|c|c|c|c|c|c|c|c|c|c|c|c|}
\hline \multirow{2}{*}{ Microorganism } & \multicolumn{12}{|c|}{ Period ${ }^{*}$} \\
\hline & Jan & Feb & Mar & Apr & May & Jun & Jul & Aug & Sept & Oct & Nov & Dec \\
\hline Not identified & 9.8 & 4.9 & 12.2 & 7.3 & 7.3 & 7.3 & 7.3 & 9.8 & 12.2 & 12.2 & & 9.8 \\
\hline S. epidermidis & 11.9 & 5.6 & 9.4 & 6.3 & 10 & 5 & 6.9 & 6.9 & 6.3 & 10 & 12.5 & 9.4 \\
\hline S. aureus & 8.2 & 11.2 & 9.2 & 8.2 & 8.2 & 7.1 & 11.2 & 6.1 & 9.2 & 6.1 & 6.1 & 9.2 \\
\hline Streptococcus sp. & 8.1 & 10.8 & 8.1 & 8.1 & 18.9 & 2.7 & 10.8 & 10.8 & 10.8 & 5.4 & 2.7 & 2.7 \\
\hline Enterococcus sp. & & 11.8 & & 11.8 & 17.6 & 5.9 & & 17.6 & 5.9 & 11.8 & 5.9 & 11.8 \\
\hline Pseudomonas sp. & 16.7 & 16.7 & & 11.1 & 16.7 & 5.6 & 11.1 & & 11.1 & 0 & 5.6 & 5.6 \\
\hline Escherichia Coli & 3.2 & 16.1 & 6.5 & 6.5 & 9.7 & 3.2 & 6.5 & 3.2 & 6.5 & 12.9 & 12.9 & 12.9 \\
\hline Negative culture & 11.2 & 7.1 & 6.1 & 9.2 & 8.2 & 5.1 & 9.2 & 17.3 & 7.1 & 10.2 & 4.1 & 5.1 \\
\hline Enterobacter & & 6.7 & 13.3 & 6.7 & 6.7 & & 13.3 & 6.7 & & 6.7 & 26.7 & 13.3 \\
\hline Klebsiella & 35.3 & 5.9 & 5.9 & 5.9 & & & & 17.6 & 5.9 & 11.8 & & 11.8 \\
\hline \multirow[t]{2}{*}{ Others } & 4.2 & & 4.2 & 12.5 & 16.7 & 12.5 & 16.7 & & 4.2 & 4.2 & 8.3 & 16.7 \\
\hline & 9.8 & 4.9 & 12.2 & 7.3 & 7.3 & 7.3 & 7.3 & 9.8 & 12.2 & 12.2 & & 9.8 \\
\hline
\end{tabular}

* Percentages obtained based on the total of each microorganism. 
Other studies corroborate our findings of gram-negative germs being significantly higher in the summer months [16] [19] [20]. However, the study by Kim et al. [17] stated that gram-negative peritonitis occurred uniformly throughout the year, while the rate of peritonitis caused by gram-positive germs increased in the hot and humid months. A consistency in peritonitis caused by gram-positive germs was observed in our sample throughout the year, with a peak occurring in May and a significant decrease in June.

It was shown in two studies evaluating the existence of seasonal variations and infections that Staphylococcus epidermidis and negative cultures were more frequent during the warmer months of the year [20] [21], unlike our findings where this germ was found to be more prevalent in the spring and the negative culture in the winter.

Cho et al. [16] demonstrated that there was a tendency for seasonal variations of peritonitis caused by fungi in the summer, with a peak in the fall. Our findings showed a tendency for peritonitis by fungi to occur in more frequently in April (fall). This same study showed there was no seasonal variation for Streptococcus sp. and Enterococcus sp., which differs from our results in which Streptococcus sp. was more prevalent in May (fall) and Enterococcus sp. in the months of May (fall) and August (winter).

Studies by Chan et al. [21] and Cho et al. [21] observed that the occurrences of peritonitis caused by Staphylococcus aureus were uniformly distributed throughout the year, which is consistent with our study. Staphylococcus aureus is a microorganism that naturally inhabits the skin, such as on the hands and around the catheter exit-site, and this can therefore justify the uniformity of peritonitis caused by it throughout all the year [21].

Even in hemodialysis patients there is a $46 \%$ risk increase for the development of septicemia associated with the central venous catheter in the summer months, which may or may not be related to the susceptibility of chronic kidney patients [20].

The main limitation of this study is in its being retrospective, without records for the temperatures over the years, nor information related to catheter exit-site infections. It is known that despite the south of Brazil having a temperate climate, there is a great variation in temperature within the same season of the year.

This research brings to the spotlight an important issue in peritoneal dialysis, peritonitis that is still cause of mortality in this group of patients. Identifying risk factor such as the influence of season can help health care professional to act upon this and re-train patients beforehand. Further research in this area can improve outcomes in peritoneal dialysis.

\section{Conclusions}

The rate of peritonitis is in line with that recommended by the ISPD. Gram-positive bacteria caused the majority of episodes with an even distribution over the months of the year, which suggests that seasonality has no impact on the occurrence of peritonitis. The distribution of peritonitis-causing microorganisms over the months of the year would seem to be by chance.

Although no significant incidence was found in respect of microorganisms and the months of the year, it is important to know that there is a higher occurrence in the summer months so that surveillance measures and patient retraining can be established.

\section{References}

[1] Cho, Y. and Johnson, D.W. (2014) Peritoneal Dialysis-Related Peritonitis: Towards Improving Evidence, Practices, and Outcomes. American Journal of Kidney Diseases: The Official Journal of the National Kidney Foundation, 64, 278289. http://dx.doi.org/10.1053/j.ajkd.2014.02.025

[2] Chaudhary, K. (2011) Peritoneal Dialysis Drop-Out: Causes and Prevention Strategies. International Journal of Nephrology, 2011, Article ID: 434608. http://dx.doi.org/10.4061/2011/434608

[3] Bender, F.H., Bernardini, J. and Piraino, B. (2006) Prevention of Infectious Complications in Peritoneal Dialysis: Best Demonstrated Practices. Kidney International Supplement, 70, S44-S54. http://dx.doi.org/10.1038/sj.ki.5001915

[4] Figueiredo, A.E., Poli de Figueiredo, C.E. and d'Avila, D.O. (2000) Peritonitis Prevention in CAPD: To Mask or Not? Peritoneal Dialysis International: Journal of the International Society for Peritoneal Dialysis, 20, 354-358.

[5] Wong, C., Luk, I.W., Ip, M. and You, J.H. (2014) Prevention of Gram-Positive Infections in Peritoneal Dialysis Patients in Hong Kong: A Cost-Effectiveness Analysis. American Journal of Infection Control, 42, 412-416. http://dx.doi.org/10.1016/j.ajic.2013.12.008

[6] Barretti, P., Moraes, T.M., Camargo, C.H., Caramori, J.C., Mondelli, A.L., Montelli, A.C., et al. (2012) Peritoneal Dialysis-Related Peritonitis Due to Staphylococcus aureus: A Single-Center Experience over 15 Years. PloS ONE, 7, 
e31780. http://dx.doi.org/10.1371/journal.pone.0031780

[7] Figueiredo, A.E., Poli de Figueiredo, C.E. and d’Avila, D.O. (2001) Bag Exchange in Continuous Ambulatory Peritoneal Dialysis without Use of a Face Mask: Experience of Five Years. Advances in Peritoneal Dialysis Conferenceon Peritoneal Dialysis, 17, 98-100.

[8] Figueiredo, A.E., Poli-de-Figueiredo, C.E., Meneghetti, F., Lise, G.A., Detofoli, C.C. and Silva, L.B. (2013) Peritonitis in Patients on Peritoneal Dialysis: Analysis of a Single Brazilian Center Based on the International Society for Peritoneal Dialysis. Jornal brasileiro de nefrologia: Orgao oficial de Sociedades Brasileira e Latino-Americana de Nefrologia, 35, 214-219. http://dx.doi.org/10.5935/0101-2800.20130034

[9] Johnson, D.W., Clark, C., Isbel, N.M., Hawley, C.M., Beller, E., Cass, A., et al. (2009) The Honeypot Study Protocol: A Randomized Controlled Trial of Exit-Site Application of Medihoney Antibacterial Wound Gel for the Prevention of Catheter-Associated Infections in Peritoneal Dialysis Patients. Peritoneal Dialysis International: Journal of the International Society for Peritoneal Dialysis, 29, 303-309.

[10] Al-Hwiesh, A.K. and Abdul Rahman, I.S. (2008) Prevention of Staphylococcal Peritonitis in CAPD Patients Combining Ablution and Mupirocin. Saudi Journal of Kidney Diseases and Transplantation: An Official Publication of the Saudi Center for Organ Transplantation, Saudi Arabia, 19, 737-745.

[11] Nessim, S.J., Komenda, P., Rigatto, C., Verrelli, M. and Sood, M.M. (2013) Frequency and Microbiology of Peritonitis and Exit-Site Infection among Obese Peritoneal Dialysis Patients. Peritoneal Dialysis International: Journal of the International Society for Peritoneal Dialysis, 33, 167-174. http://dx.doi.org/10.3747/pdi.2011.00244

[12] Nouwen, J.L., Fieren, M.W., Snijders, S., Verbrugh, H.A. and van Belkum, A. (2005) Persistent (Not Intermittent) Nasal Carriage of Staphylococcus aureus is the Determinant of CPD-Related Infections. Kidney International, 67, 10841092. http://dx.doi.org/10.1111/j.1523-1755.2005.00174.x

[13] Moraes, T.P., Pecoits-Filho, R., Ribeiro, S.C., Rigo, M., Silva, M.M., Teixeira, P.S., Pasqual, D.D., Fuerbringer, R. and Riella, M.C. (2009) Peritoneal Dialysis in Brazil: Twenty-Five Years of Experience in a Single Center. Peritoneal Dialysis International: Journal of the International Society for Peritoneal Dialysis, 29, 492-498.

[14] Li, P.K., Szeto, C.C., Piraino, B., Bernardini, J., Figueiredo, A.E., Gupta, A., et al. (2010) Peritoneal Dialysis-Related Infections Recommendations: 2010 Update. Peritoneal Dialysis International: Journal of the International Society for Peritoneal Dialysis, 30, 393-423. http://dx.doi.org/10.3747/pdi.2010.00049

[15] Sesso Rde, C., Lopes, A.A., Thome, F.S., Lugon, J.R., Watanabe, Y. and Santos, D.R. (2012) Chronic Dialysis in Brazil: Report of the Brazilian Dialysis Census, 2011. Jornal brasileiro de nefrologia: Orgao oficial de Sociedades Brasileira e Latino-Americana de Nefrologia, 34, 272-277. http://dx.doi.org/10.5935/0101-2800.20120009

[16] Cho, Y., Badve, S.V., Hawley, C.M., McDonald, S.P., Brown, F.G., Boudville, N., et al. (2012) Seasonal Variation in Peritoneal Dialysis-Associated Peritonitis: A Multi-Centre Registry Study. Nephrology, Dialysis, Transplantation: Official Publication of the European Dialysis and Transplant Association-European Renal Association, 27, 2028-2036. http://dx.doi.org/10.1093/ndt/gfr582

[17] Kim, M.J., Song, J.H., Park, Y.J., Kim, G.A. and Lee, S.W. (2000) The Influence of Seasonal Factors on the Incidence of Peritonitis in Continuous Ambulatory Peritoneal Dialysis in the Temperate Zone. Advances in Peritoneal Dialysis Conference on Peritoneal Dialysis, 16, 243-247.

[18] Dos Santos, R.P., Konkewicz, L.R., Nagel, F.M., Lisboa, T., Xavier, R.C., Jacoby, T., et al. (2013) Changes in Hand Hygiene Compliance after a Multimodal Intervention and Seasonality Variation. American Journal of Infection Control, 41, 1012-1016. http://dx.doi.org/10.1016/j.ajic.2013.05.020

[19] Szeto, C.C., Chow, K.M., Wong, T.Y., Leung, C.B. and Li, P.K. (2003) Influence of Climate on the Incidence of Peritoneal Dialysis-Related Peritonitis. Peritoneal Dialysis International: Journal of the International Society for Peritoneal Dialysis, 23, 580-586.

[20] Lok, C.E., Thumma, J.R., McCullough, K.P., Gillespie, B.W., Fluck, R.J., Marshall, M.R., et al. (2014) Catheter-Related Infection and Septicemia: Impact of Seasonality and Modifiable Practices from the DOPPS. Seminars in Dialysis, 27, 72-77. http://dx.doi.org/10.1111/sdi.12141

[21] Bernardini, J., Price, V. and Figueiredo, A. (2006) Peritoneal Dialysis Patient Training. Peritoneal Dialysis International: Journal of the International Society for Peritoneal Dialysis, 26, 625-632. 
Scientific Research Publishing (SCIRP) is one of the largest Open Access journal publishers. It is currently publishing more than 200 open access, online, peer-reviewed journals covering a wide range of academic disciplines. SCIRP serves the worldwide academic communities and contributes to the progress and application of science with its publication.

Other selected journals from SCIRP are listed as below. Submit your manuscript to us via either submit@scirp.org or Online Submission Portal.
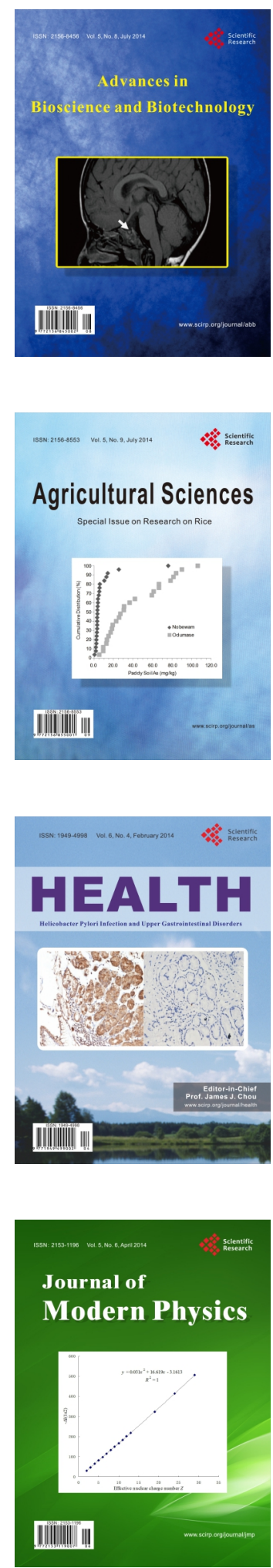
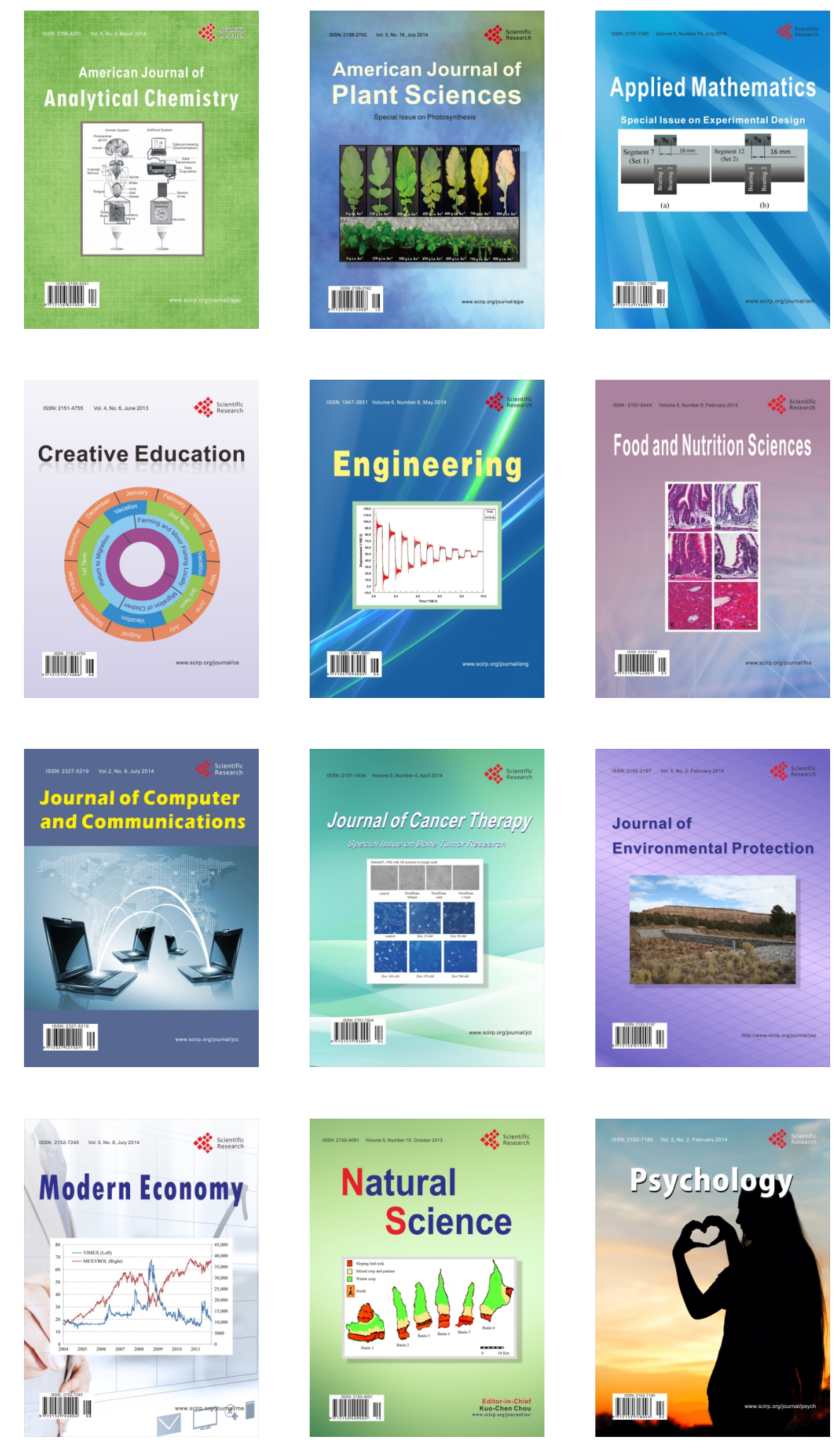